\title{
Agricultural Land Cover Change in Gazipur, Bangladesh, in Relation to Local Economy Studied Using Landsat Images
}

\author{
Tarulata Shapla1,2, Jonggeol Park ${ }^{3}$, Chiharu Hongo', Hiroaki Kuze ${ }^{1}$ \\ ${ }^{1}$ Center for Environmental Remote Sensing, Chiba University, Chiba, Japan \\ ${ }^{2}$ Department of Agroforestry and Environmental Science, Sher-e-Bangla Agricultural University, \\ Dhaka, Bangladesh \\ ${ }^{3}$ Graduate School of Informatics, Tokyo University of Information Sciences, Chiba, Japan \\ Email: tarulatashapla@chiba-u.jp
}

Received 17 June 2015; accepted 21 August 2015; published 24 August 2015

Copyright (C) 2015 by authors and Scientific Research Publishing Inc.

This work is licensed under the Creative Commons Attribution International License (CC BY).

http://creativecommons.org/licenses/by/4.0/

(c) () D Den Access

\section{Abstract}

Land classification is conducted in Gazipur district, located in the northern neighborhood of Dhaka, the capital of Bangladesh. Images of bands 1 - 5 and 7 of Landsat 4 - 5 TM and Landsat 7 ETM+ imagery recorded in years 2001, 2005 and 2009 are classified using unsupervised classification with the technique of image segmentation. It is found that during the eight year period, paddy area increased from $30 \%$ to $37 \%$, followed by the increase in the homestead (55\% to $57 \%$ ) and urban area $(1 \%$ to $3 \%)$. These changes occurred at the expense of the decrease in forest land cover $(14 \%$ to $3 \%$ ). In the category of homestead, the presence of different kinds of vegetation often makes it difficult to separate the category from paddy field, though paddy exhibits accuracy of $93.70 \%$ $\mathbf{9 9 . 9 5 \%}$, which is better than the values for other categories. In addition, the analysis based on digital elevation model reveals that paddy cultivation is implemented in lowland rather than highland. Homestead areas have spread from south (low elevation) to north (high elevation), in association with the decrease in forest-covered areas.

\section{Keywords}

Agroforestry, Paddy, Bangladesh, Land Classification, Landsat

\section{Introduction}

The economy of Bangladesh is based on agriculture, where land is the most basic natural resource. Land sup-

How to cite this paper: Shapla, T., Park, J., Hongo, C. and Kuze, H. (2015) Agricultural Land Cover Change in Gazipur, Bangladesh, in Relation to Local Economy Studied Using Landsat Images. Advances in Remote Sensing, 4, 214-223. 
ports the rural economy, being the major focus for the poverty alleviation process. Among the current labor force, about $65 \%$ is employed in the agricultural sector. In 2009-2010, for instance, agriculture contributed 23.5\% to the country's total gross domestic product [1]. The problem, however, is that the per capita land area is one of the lowest in the world, estimated at 0.12 ha [2]. In addition, the mostly unplanned economic growth in the past has led to environmental degradation and adversely affected the resilience of society. Among various issues such as agriculture, water, energy, climate change, disaster risk reduction and disaster management, food security can be considered as the key priority for sustainable development in Bangladesh [3].

Rice is the dominant economic crop in Bangladesh. In 2000-2001, rice alone occupied $75 \%$ of the cultivable land [4], which increased to 79.4\% in 2008 [5]. In 2013, over 11.7 million hectares of land in Bangladesh is dedicated to rice production. Economically, rice dominates with $71 \%$ share, on average, of the gross output value of all crops [6]. Since the dominance of rice in the crop sub-sector virtually assures stability in the structure of food production, major shifts in the crop diversification will be limited as long as rice is important in the diet of the nation as staple food, though optimized use of land can bring prosperity in production and growth. Although numerous pieces of fallow lands are available throughout the country, these are often very poorly managed and utilized. Any cultivable land outside farm plot and homestead may come under this category of agroforestry. In consideration of the location and size of the plot as well as the status and economic condition of the land owner/ user, suitable agroforestry modules (units or items such as trees, fruits, vegetable, crops, etc.) can be introduced for proper utilization of the land and maximum economic return [7].

In Bangladesh, the topographical situations along with availability of water and subtropical climate constitute an excellent habitat for rice cultivation. Currently $80 \%$ of the country's rice-growing land is cultivated with varieties developed by Bangladesh Rice Research Institute (BRRI). Three types of rice (Oryza sativa subsp. indica) are grown in different seasons, namely, Aus, Aman and Boro. According to the Bangladesh Bureau of Statistics (BBS) report in 2009 [8], these three species cover 1.07, 5.48 and 4.72 million ha of land, respectively. Also, these rice types correspond to different rice ecosystems: namely, direct-seeded pre-monsoon (Aus in upland, July-August), irrigated (mainly Boro in the dry-season, March-May), and rain fed lowland (Aman, DecemberJanuary, mainly transplanted in medium-deep stagnant water of $50-100 \mathrm{~cm}$ in depth) cultivation [9]. These varieties together contribute about $74 \%$ to the total annual rice production of the country. Because of the double or triple cropping, Boro, Aus, and Aman occupy 90\%, 25\% - 30\%, and 50\% - 55\%, respectively, in terms of area coverage [10].

Using satellite imagery, a number of researchers have conducted investigations that are related to the change detection of land use and land cover (LULC) in Bangladesh. For example, major land cover types and their changes were monitored in Bangladesh in the two time periods of 1985-1986 and 1992-1993 using NOAA AVHRR satellite data [11]. Similarly, AVHRR channels 1 and 2 data from 1984 to 1985 were used to calculate normalized difference vegetation index (NDVI), which was found to be a useful index for monitoring vegetation conditions in Bangladesh [12]. Maximum likelihood and sub-pixel classification schemes were employed for detecting mangrove forest cover change in Sundarbans in southwest Bangladesh from 1989 to 2000 using Landsat Thematic Mapper (TM) satellite imagery [13]. Increase in built-up areas in Dhaka city from 46\% to 58\% during 2009-2019 is evaluated and predicted with multi-layer perceptron Markov model using Landsat imagery [14].

In order to accomplish and maintain sustainable development, it is imperative that monitoring of LULC changes is carried out at regular intervals. According to the 2007 report of Food and Agriculture Organization (FAO) [15], for instance, cultivated land covers $56 \%$ of the land area in the country, followed by villages (19\%), inland water (14\%), forest (10\%), and built up area (1\%). According to the 2008 report of BBS, on the other hand, $52.5 \%$ of the area is classified as cultivated land, $9 \%$ as inland water, $17.5 \%$ as forest, and about $5.1 \%$ as built up area [8]. Such inconsistency in the land cover statistics infers the need for more systematic approach for monitoring the land cover change in various parts of the country, and obviously, satellite image analysis is potentially valuable for such LULC change monitoring. In this context, the purpose of the present study is to examine the recent LULC changes in Gazipur area, in the northern neighbor of the capital Dhaka district. As explained in the next section, the area provides us with a typical case in the mid-altitude region of the country, in that the whole area is suitable for rice growing, but at the same time, it is under the socio-economical pressure of growing population, urbanization, and industrialization. The Landsat images taken in years 2001, 2005, and 2009 are employed for the LULC analysis. By virtue of the high-resolution (30 m/pixel) property of Landsat imagery, the separation among paddy, forest, and homestead areas can be carried out, with reasonable correspondence to validation data taken during our ground survey conducted in 2013-2014. 


\section{Study Area}

The present research area is Gazipur (Figure 1), which is in the northern outskirts of Dhaka, the capital city of Bangladesh. The area is located between latitude $23.88^{\circ}-24.34^{\circ}$ and longitude $90.15^{\circ}-90.70^{\circ}$. Gazipur is situated in Old Brahmaputra (floodplains) and Madhupur tract (terraces). The main rivers in this district are Old Brahmaputra, Shitalakshya, Turag, Bangshi, Balu, and Banar. Annual average temperature varies from 13 to $36^{\circ} \mathrm{C}$. Annual rainfall is around $2400 \mathrm{~mm}$. There are five sub-districts (Upazilla) in Gazipur, namely, Gazipur Sadar, Kaliakair, Kaliganj, Kapasia and Sreepur, as indicated in Figure 1. According to the BBS statistics in 2011 [8], the total population and population density of Gazipur district is 34,03,912 and $1884 \mathrm{~km}^{-2}$, respectively, with annual growth rate of 5.2\%. The literacy rate of Gazipur district is 62.60\% [8]. Agro-ecologically, the study area belongs to AEZ-9 and 28 categories of FAO of the United Nations [16]. Rice of local and high yielding varieties (HYV), jute, vegetables, etc., are important agricultural products with relatively high economic impact, in addition to the forest products such as wood, wood fuel, wood pulp, forage etc. In terms of agricultural research institutes in Bangladesh, major organizations such as BRRI, BARI and university that has faculty in relation to agriculture are located in Gazipur. Also, the area has experienced rapid advancement in the industrial sector such as machine tool factories, a diesel plant, packaging industry, brick field manufacturers, etc., all of which can contribute to the regional economic development in the foreseeable future.

\section{Satellite and Other Data Sources}

The analysis of this study is implemented for the following two types of satellite images: Landsat 4 - 5 Thematic Mapper (TM) (16 January 2005 with 0\% cloud cover and 11 January 2009 with 1\% cloud cover) and Landsat 7 Enhanced Thematic Mapper Plus (ETM+) (29 January 2001 with 0\% cloud cover). The present choice of January images is based on the fact that such nearly cloud-free data are available only in the dry winter season. Because of the choice, the paddy condition is for monitoring the growing phase of Boro rice. The analysis of satellite data in the same season is beneficial for attaining better comparison in different time periods, enabling the extraction of meaningful changes in LULC. Data are analyzed using the information from bands $1-5$ and 7 (Table 1). The ETM+ sensor has a spatial resolution of $30 \mathrm{~m}$ for visible (bands 1 - 3), near-infrared (NIR) (band 4 and 5) and shortwave infrared (SWIR) (band 7) wavelengths. The resolution of TM is the same for the blue to mid-IR reflectance bands. Landsat images were acquired from the USGS Global Visualization Viewer (http://glovis.usgs.gov/).

For the purpose of ground-reference evaluation of the classification results, we extracted 38 areas (4535 pixels in total) from the Google Earth imagery, which is originally based on the Digital Globe imagery observed in 2007 and 2010. Each area has 120 pixels, on average, and consequently, the pixel size unit of each area is around $11 \times 11\left(330 \times 330 \mathrm{~m}^{2}\right)$. Also, we employed 262 images taken with a GPS camera occasionally in 2013 and 2014. The topographic feature of the area is obtained from the digital elevation model (DEM) data based on

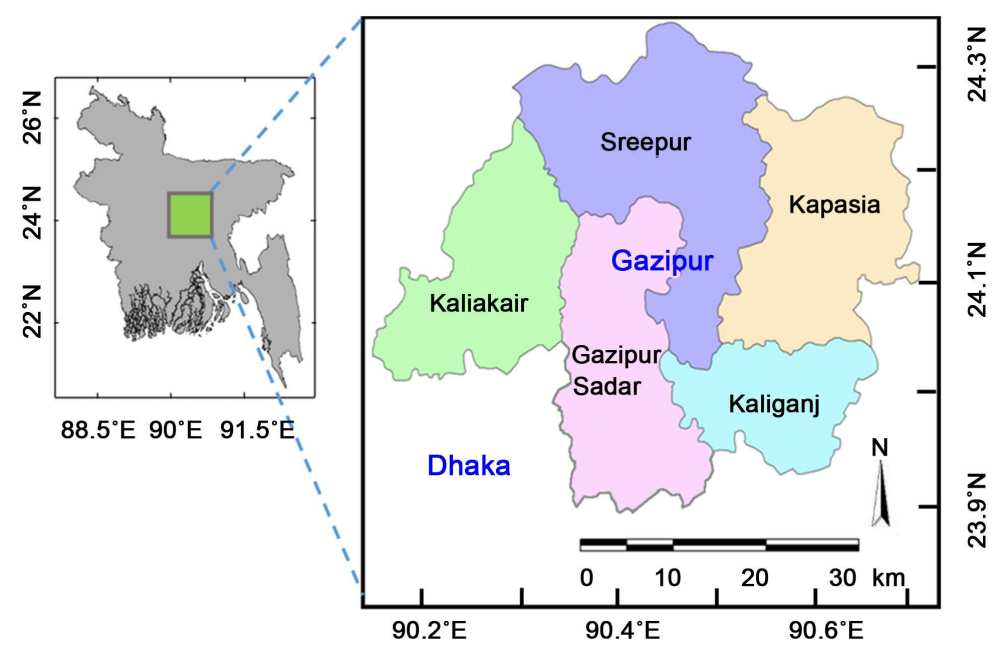

Figure 1. Gazipur district in the northern outskirts of Dhaka. There are five subdistricts: Gazipur Sadar, Kaliakair, Kaliganj, Kapasia and Sreepur. 
Table 1. Wavelength range of Landsat bands (nm).

\begin{tabular}{ccc}
\hline \multirow{2}{*}{ Band } & \multicolumn{2}{c}{ Satellite/Sensor } \\
\cline { 2 - 3 } & Landsat $4-5$ TM & Landsat 7/ETM+ \\
\hline 2 & $450-520$ & $450-520$ \\
3 & $530-600$ & $530-610$ \\
4 & $630-690$ & $630-690$ \\
5 & $760-900$ & $750-900$ \\
7 & $1550-1750$ & $1550-1750$ \\
\hline
\end{tabular}

the Shuttle Radar Topography Mission (SRTM) with a resolution of $90 \mathrm{~m}$. Originally SRTM data were obtained in the mission of the Space Shuttle Endeavour during an 11-day flight in February 2000 (http://dds.cr.usgs.gov/srtm/version2_1/SRTM3/Eurasia).

\section{Segmentation and Classification}

Figure 2 shows the flow of the data analysis in the present study. Three satellite data were subjected to the segmentation analysis, which is the foundation for an object-based classification. It is the process of subdividing an image composed of a number of different image objects. For controlling segmentation procedure, Liu and Yamazaki [17] adopted the following four parameters: scale parameter (allowed level of in homogeneity in an object), layer weight (weight for each band), and shape factor (weight of spectral and shape features), and compactness (compactness of each object). In order to reduce the noise, the object-based segmentation is employed rather than the pixel-based segmentation. The values actually utilized in the present research are 5, 0.1, and 0.5 for scale parameter, shape factor, and compactness, respectively. The same value of unity is assumed for the layer weight of all bands. The choice of these parameters has contributed to the separation between forest and paddy classes.

In the present study, we use band $5(1.65 \mu \mathrm{m})$ and band $7(2.22 \mu \mathrm{m})$ of Landsat TM and ETM+ in addition to bands $1-4$, since these two bands with longer wavelengths are less susceptible to the atmospheric influence than shorter wavelength bands (bands 1 - 4). By using the data for three different acquisition times (2001, 2005, and 2009), change detection has been achieved in the Gazipur area.

After the segmentation, unsupervised classification algorithm (ISODATA) is applied to classify the segmented images into four different classes, i.e., homestead, paddy, forest and urban. Prior to this procedure, the water bodies in association with major rivers are removed by applying masks (with the help of visual interpretation), since the discrimination between paddy and water body is often difficult. The major characteristics of these four categories can be described as follows. Paddy field is the arable land used for paddy cultivation. Forest indicates lands covered with deciduous forest, mixed forest and others. Homestead is the land used for the production of multipurpose trees, various fruits, vegetables, spices, fodder, forage, fuel wood and ornamental herbs/shrubs: recently such small-scale agriculture has increased considerably in the rural areas of Bangladesh [18]. The category of urban area stands for residential, commercial and services, industrial, transportation, roads, mixed urban and other urban structures.

\section{Results and Discussion}

\subsection{Topography and Land Cover}

The topographic feature of Gazipur was derived from the SRTM DEM data. Here the combination of the DEM information and the classification result of Landsat 2009 image (as described below) is exploited for the examination of altitude distribution of each land coverage type (homestead, paddy, forest and urban) (Figure 3). In Bangladesh, the great plain lies almost at sea level along the southern coast and the land elevation rises gradually toward the north. Since Gazipur area is in the mid of the great plain, it is included in medium-high to highland, i.e., 4 - $24 \mathrm{~m}$ above sea level (ASL). In highland (20 - $30 \mathrm{~m} \mathrm{ASL),} \mathrm{the} \mathrm{elevation} \mathrm{is} \mathrm{above} \mathrm{the} \mathrm{normal} \mathrm{flood}$ 


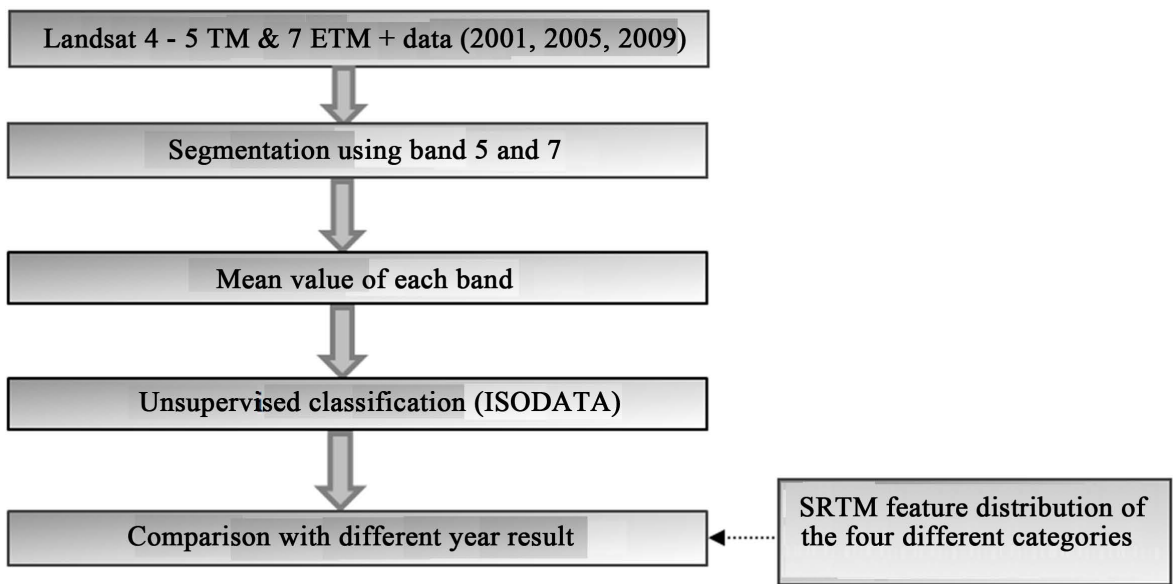

Figure 2. Flow of the data analysis in the present study.

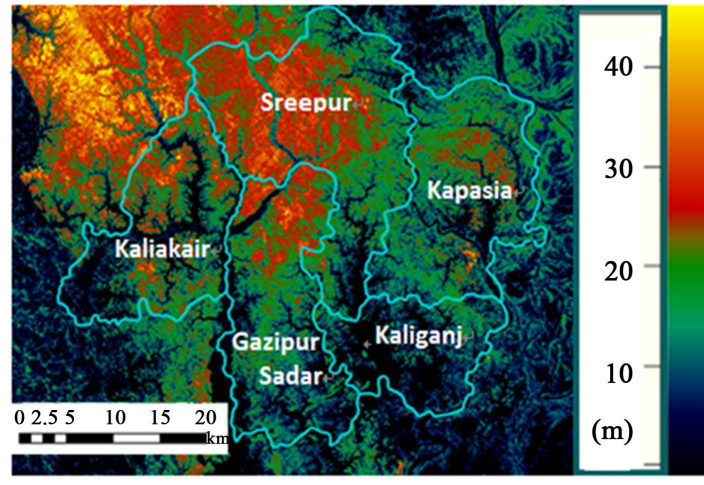

(a)

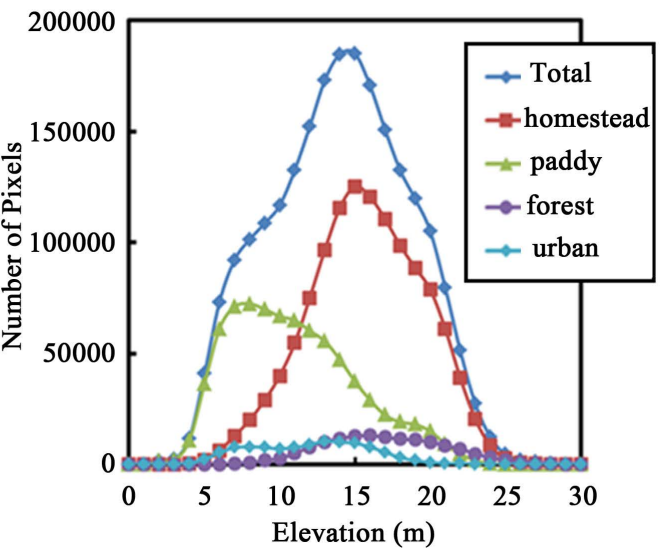

(b)

Figure 3. Topographical condition of Gazipur (a) Digital elevation map generated from SRTM data, and (b) Elevation distribution histograms for homestead, paddy, forest and urban areas.

level, while the medium-high area (below $20 \mathrm{~m}$ ASL) is normally flooded to the maximum depth of around 90 $\mathrm{cm}$ during the monsoon season from June to September.

In Gazipur, homestead and forest areas are located in mid to high elevation areas, while paddy areas are found normally in lowland areas. From SRTM observation shown in Figure 3(a), it can be seen that western part of Gazipur is occupied by high land (>20 m ASL), whereas eastern part has middle to low range of elevation. Among the five sub-districts, land elevation is relatively high in Sreepur (northern area), while it is relatively low in Kaliganj (south-eastern area). As indicated in Figure 3(b), low-land areas (southern part) have many paddy areas owing to low topographical conditions. Other than paddy, the low land area is covered with floodplains, depressions, abandoned channels, swamps, and marshes. Also, the height of the land gradually increases from east to west: in the western part the highland is often called the Dhaka terrace, which is dissected by the tributaries of the Turag, the Buriganga and the Balur rivers. The elevation of Dhaka terrace ranges from 6.1 to $11.3 \mathrm{~m}$ ASL.

\subsection{Land Cover Change}

Figure 4 shows the classified images and area statistics obtained from the analysis of 2001, 2005, and 2009 Landsat data. Over the eight year time period, homestead areas expanded from 55\% to 57\%. In Kaliakair (western sub-district of Gazipur), homestead increased gradually. In Sreepur, Kaliganj and Kapasia, the homestead coverage was more or less unchanged, whereas in Gazipur Sadar homestead areas exhibited a declining trend from 2005 to 2009. The paddy field fraction has increased from 30\% (2001) to $35 \%$ (2005) and 37\% (2009). As 

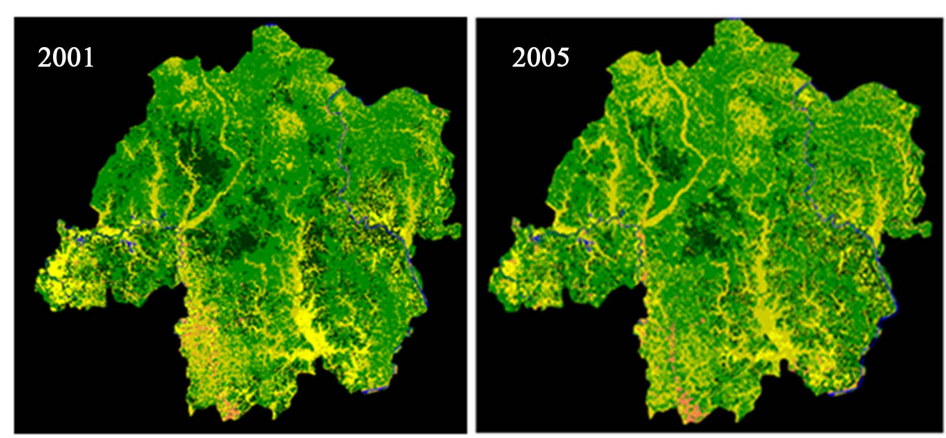

(a)

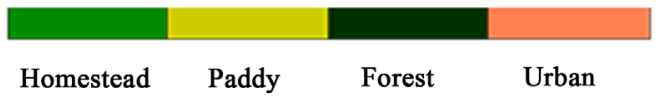

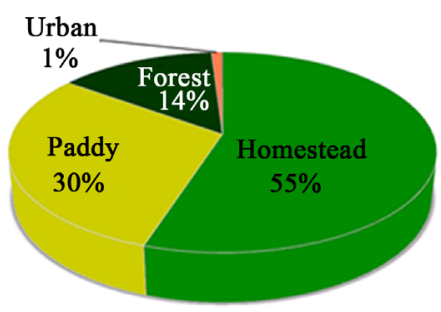

2001

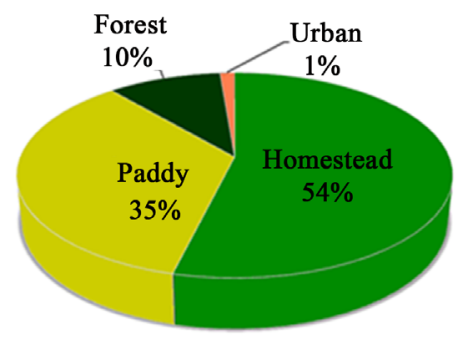

2005
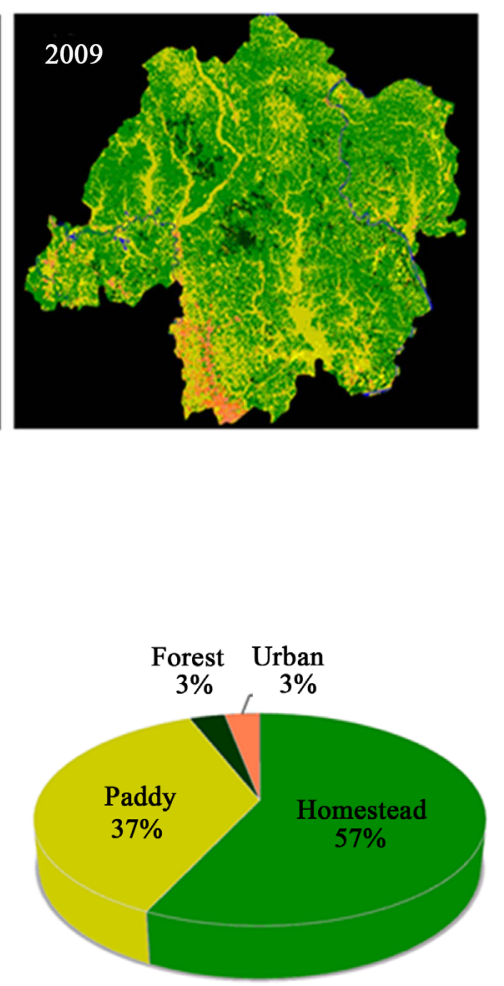

2009

(b)

Figure 4. Classification results (a) Classification maps of Landsat images for 2001, 2005, and 2009; and (b) Pie charts showing the statistics.

indicated in the SRTM DEM analysis (Figure 3), most of the increase was found in the lowland. In Sreepur (northern sub-district), paddy area steadily increased till 2009. In Gazipur Sadar, on the other hand, paddy area decreased from 2001 to 2005, and it increased again till 2009. Significant increase in paddy coverage was found in Kaliakair, Kapasia and Kaliganj sub-districts.

Urban area occupied 1\% in 2001, which increased to 1.3\% in 2005 and 3\% in 2009. This change was observed especially in Gazipur Sadar, followed by Kaliakair. From Figure 4(a), it is evident that the rapid urbanization has occurred in the Gazipur-Sadar sub-district, in the vicinity of the capital Dhaka area. An important implication of growing urbanization is that some of the fertile agricultural land had to be converted to other uses. In the whole Bangladesh, close to $1 \%$ agricultural land is being lost every year to other uses including settlements for growing population [3], which is a potential threat to food security.

In contrast to the increase in the three categories mentioned above, the decrease in forest covered areas (14\%, $10 \%$, and $3 \%$ in 2001, 2005, and 2009, respectively) is noteworthy. Such decrease in forest cover is found especially in Sreepur (northern part). It is estimated that $25 \%$ to $26 \%$ of wood production in Bangladesh is used for burning bricks every year, causing deforestation. This is an alarming trend for environment because of the frequent incidence of drought-spells with the visually identifiable trend of desertification [19]. Serious environmental impacts of deforestation would generally include loss of habitats and bio-diversity, undesirable changes in local ecology, changes in microclimate, loss of carbon sink, soil erosion, less water retention, increased flooding, etc. The central Sal forest is distributed in Dhaka, Gazipur and some other districts of Bangladesh, corresponding to $86 \%$ of the Sal forest in the whole country. Anthropogenic threats such as over exploitation, illegal cutting, expanding agriculture, urbanization, pollution, as well as natural threats are the major causes of deforestation of Sal forest. According to the satellite data in 2009, forest coverage fraction was $28 \%$ in Sreepur, $11 \%$ in Kaliganj and Kaliakair, 19\% in Kapasia, and 31\% in Gazipur Sadar. According to the BBS report 2011 of Gazipur [8], on the other hand, 33\% area in Sreepur was forest, whereas in Kaliakair, Kapasia, Gazipur Sadar, and Kaliganj, the forest fractions were $27 \%, 20 \%, 20 \%$ and $0 \%$, respectively. The lack of forest area in Kaliganj, 
the south-eastern sub-district, is ascribed to a large-scale development of industrial complex that started in 2009. This destroyed nearly 1600 acres of crop land, forests, orchards and water bodies in Kaliganj for creating Purbachal New Town at about $16 \mathrm{~km}$ from the capital [20].

\subsection{Validation of Classification Results}

We conducted an extensive field survey using the global positioning system (GPS) from September 2013 to January 2014 to verify the classification results. Also with the help of the Google Earth imagery, the accuracy tables for the classification results in 2001, 2005, and 2009 are summarized in Table 2. Here the total number of validation pixels is 4535, corresponding to 38 points (areas) selected for the ground reference (GR).

Table 2. Accuracy table for the classification results in 2001, 2005, and 2009.

\begin{tabular}{|c|c|c|c|c|c|c|}
\hline GR & Homestead & Paddy & Forest & Urban & Total & $\kappa$ value \\
\hline \multicolumn{7}{|l|}{2001} \\
\hline \multirow[t]{2}{*}{ Homestead } & 972 & 18 & 398 & 0 & 1388 & 0.745 \\
\hline & 70.03 & 1.30 & 28.67 & 0.00 & 100.00 & \\
\hline \multirow[t]{2}{*}{ Paddy } & 117 & 1740 & 0 & 0 & 1857 & \\
\hline & 6.30 & 93.70 & 0.00 & 0.00 & 100.00 & \\
\hline \multirow[t]{2}{*}{ Forest } & 180 & 0 & 897 & 0 & 1077 & \\
\hline & 16.71 & 0.00 & 83.29 & 0.00 & 100.00 & \\
\hline \multirow{2}{*}{ Urban } & 3 & 69 & 0 & 141 & 213 & \\
\hline & 1.41 & 32.39 & 0.00 & 66.20 & 100.00 & \\
\hline \multicolumn{7}{|l|}{2005} \\
\hline \multirow[t]{2}{*}{ Homestead } & 1300 & 73 & 15 & 0 & 1388 & 0.852 \\
\hline & 93.66 & 5.26 & 1.08 & 0.00 & 100.00 & \\
\hline \multirow[t]{2}{*}{ Paddy } & 1 & 1856 & 0 & 0 & 1857 & \\
\hline & 0.05 & 99.95 & 0.00 & 0.00 & 100.00 & \\
\hline \multirow[t]{2}{*}{ Forest } & 351 & 0 & 726 & 0 & 1077 & \\
\hline & 32.59 & 0.00 & 67.41 & 0.00 & 100.00 & \\
\hline \multirow[t]{2}{*}{ Urban } & 5 & 7 & & 201 & 213 & \\
\hline & 2.35 & 3.29 & 0.00 & 94.37 & 100.00 & \\
\hline \multicolumn{7}{|l|}{2009} \\
\hline \multirow[t]{2}{*}{ Homestead } & 1332 & 56 & 0 & 0 & 1388 & 0.820 \\
\hline & 95.97 & 4.03 & 0.00 & 0.00 & 100.00 & \\
\hline \multirow[t]{2}{*}{ Paddy } & 8 & 1849 & 0 & 0 & 1857 & \\
\hline & 0.43 & 99.57 & 0.00 & 0.00 & 100.00 & \\
\hline \multirow[t]{2}{*}{ Forest } & 329 & 0 & 748 & 0 & 1077 & \\
\hline & 30.55 & 0.00 & 69.45 & 0.00 & 100.00 & \\
\hline \multirow[t]{2}{*}{ Urban } & 146 & 3 & 0 & 64 & 213 & \\
\hline & 68.54 & 1.41 & 0.00 & 30.05 & 100.00 & \\
\hline
\end{tabular}


In the pixel-based accuracy table in 2001, correctly classified pixels are 972 (homestead), 1740 (paddy), 897 (forest), and 141 (urban area), whereas some pixels were misclassified in every class. Among the 1857 pixels that were classified as paddy for all of three different time periods, 117 pixels in 2001, 1 pixel in 2005 and 8 pixels in 2009 were misclassified as homestead. Regarding the percentage of accuracy, it is observed that paddy exhibits good results in different years $(93.70 \%$ - 99.95\%), which is better than other categories. Since the $\kappa$ values are $0.745,0.852$ and 0.820 for 2001, 2005, and 2009, respectively, it is understood that the accuracy of the present classification result is reasonable as a whole.

In the category of homestead, the presence of different kinds of vegetation often makes it difficult to separate the category from paddy field. Also, it is sometimes difficult to discriminate between paddy and water, since paddy rice plants grow well in low lying areas. This difficulty has been alleviated by using the river mask as derived from the three-year data using the very low reflectance of water surface in shortwave infrared and nearinfrared as compared with other objects.

Similarly, among the 213 pixels that belonged to urban areas, 141, 201 and 64 pixels were purely classified as urban, whereas 3 and 69 pixels, 5 and 7 pixels, and 146 and 3 pixels were misclassified as homestead and paddy in 2001, 2005, and 2009, respectively. As typically illustrated in Figure 5, the misclassification with different pixels tends to occur in association with the steady increase in the fraction of homestead during the eight year period. Since the Landsat images were taken in January in the dry season, soil contains less moisture. Thus, its reflectance becomes more or less similar to that of road or concrete in the urban category, and this can be the cause of the misclassification that occurs between the homestead and urban areas. Figure 5(b) shows the conversion from forest to homestead, exemplifying the expansion of homestead areas.

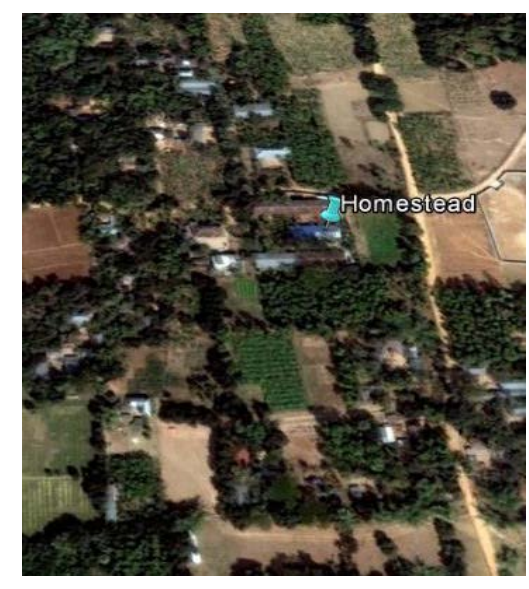

(a)
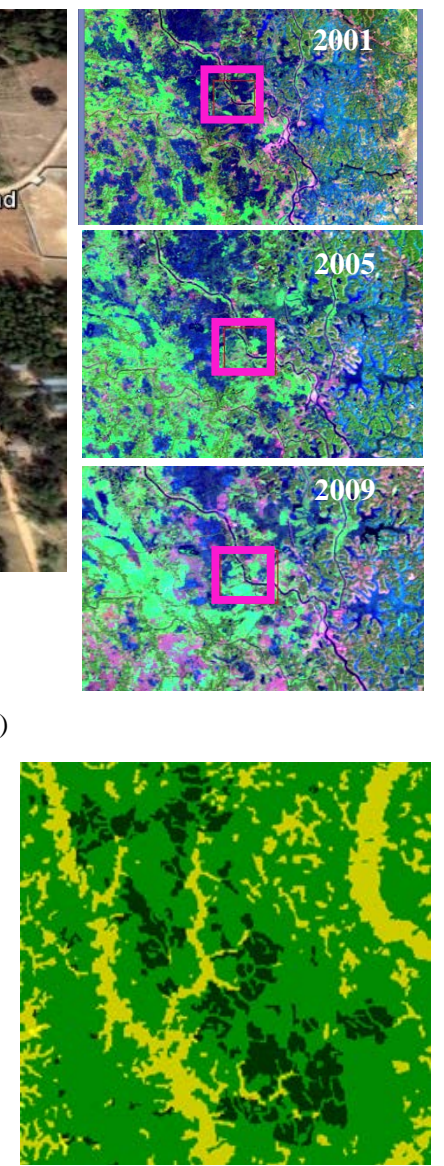

(b)

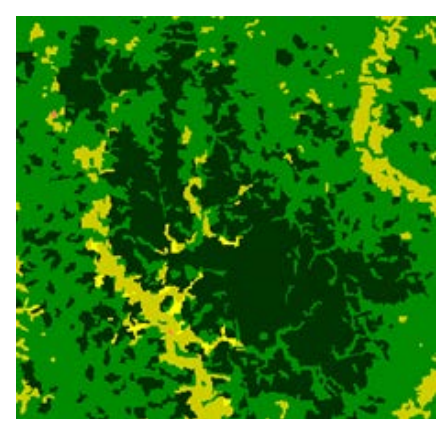

Figure 5. Homestead and forest area (a) Misclassification that occurred in the analysis of satellite images taken in 2001, 2005, and 2009; (b) Conversion from forest coverage to homestead. 


\subsection{Relation to Regional Economy and Food Security}

According to the present analysis of Landsat data, paddy area (in $\mathrm{km}^{2}$ ) in 2009 in each of the Gazipur sub-districts is 130.1 (Gazipur Sadar), 101.3 (Kaliakair), 90.3 (Kaliganj), 107.3 (Kapasia) and 158.8 (Sreepur). The BBS statistics, on the other hand, report that in 2009-2010, rice area $\left(\right.$ in $\mathrm{km}^{2}$ ) and production (in metric ton) were 113.7/32,767 (Gazipur Sadar), 43.2/26,735 (Kaliakair), 31.7/26,552 (Kaliganj), 147.8/29,298 (Kapasia), and $153.2 / 30,106$ (Sreepur) [8]. On average, the paddy areas account for $27.1 \%$ of the total area, which is slightly smaller than the satellite result of $36.5 \%\left(588 \mathrm{~km}^{2}\right)$. Nonetheless, the present analysis of satellite data has revealed that paddy area increased by around 7\% during the period from 2001 to 2009 . This recovery in the paddy area can be associated with the adoption of modern rice varieties. Although regional statistical numbers are unavailable, rice production increased by $6.4 \%$ from 2001 to 2008 in accordance with the social statistics in the whole country [8]. The change of three rice types in $2008-2009$ was $6 \%$ to $6 \%$ (Aus, no change), $41 \%$ to $37 \%$ (Aman), and 53\% to 57\% (Boro). In the harvesting periods of 2004-2005, 2005-2006 and 2006-2007, rice production was 251.57, 265.30 and 273.18 million metric tons, respectively [8]. These changes indicate the recent improvement in the food security condition, especially in availability aspect. Records say that in the 1970s, $70 \%$ of the population were under the food consumption of poverty line in Bangladesh. In 2005, however, this went down to under half of the population. As such, nutrition situation in Bangladesh has improved, as manifested in per capita energy supply from $1800 \mathrm{kcal}$ in 1970s to $3055 \mathrm{kcal}$ in 2009 [8].

The present analysis with the SRTM DEM data has revealed that homestead areas are mainly situated at a height of $\sim 16 \mathrm{~m}$ ASL, which is higher than other categories. The economic value of home gardens is the summation of the direct use values (e.g., fruit, fuel, and timber), indirect use values (e.g., soil conservation), optional values (e.g., biodiversity), existence values (e.g., endangered species), and bequest values (e.g., habitat) [13] [14].

From Table 2, it can be found that homestead accuracy was 70.03\% in 2001 and 95.97\% in 2009. In 2001, misclassification occurred with the category of forest, which is one of the components of homestead having similar spectral characteristics. One reason for the improvement in the accuracy is that gradually the forest fraction decreased, so that the accuracy in the homestead class improved in 2009. Homestead agroforestry practice and diversified food pattern can reduce the food gap [21]. A wide variety of trees, shrubs and thickets of bamboos form the groves that surround the village homesteads [8]. It is noticeable that the size of homestead forestland increases with the increase of landholding size class, but the percentage of homestead forestland in relation to total land decreases because of the devotion of higher proportion of the land to agricultural crops [22].

\section{Conclusion}

Detailed examination of land cover change has indicated the change in agroforestry conditions in Gazipur district in Bangladesh. The district is in the northern outskirts of Dhaka, and exemplifies the agricultural conditions in the midland of the country under the influence of population increase and resulting urbanization. In the present study period of 2001, 2005 and 2009, homestead areas increased by $2 \%$ and paddy area increased by $7 \%$. In the same time span, forest land decreased by $11 \%$ due to urban expansion which has turned out to be significant in Gazipur Sadar and Kaliakair sub-districts. Such forest coverage reduction is alarming for maintaining ecological equilibrium, especially when the ever increasing population of the country is considered. The changes in land cover thus detected in Gazipur are in line with those anticipated from various observations previously made on the basis of ground-based, socio-economical surveys. The approach demonstrated in the present paper will be useful for monitoring the detailed changes on the regional level, in view of the capability of satellite remote sensing for providing stable datasets over an extended time periods. Further work is in progress for better monitoring of seasonal changes in rice phenology through the interpretation with long-term satellite data.

\section{References}

[1] Bangladesh: Economy Indicators (2012) World Bank. http://www.theglobaleconomy.com/Bangladesh/indicator-NV.AGR.TOTL.ZS

[2] FAO (2001) Supplements to the Report on the 1990 World Census of Agriculture. Statistical Department Series (9a). Rome. http://www.fao.org/es/ess/census/wcahome.htm

[3] Rio + 20: May (2012) National Report on Sustainable Development. 
[4] Sustainable Development Networking Program (2001) Agricultural Database. Dhaka. http://www.sdnbd.org/sdi/issues/agriculture/index.htm

[5] FAO/WFP CFSAM Report (2008) http://en.wikipedia.org/wiki/Rice_production_in_Bangladesh

[6] http://www.apipnm.org/swlwpnr/reports/y_sa/z_bd/bd.htm

[7] Hocking, D. and Haque, M.A. (1989) Village and Farm Forestry in Bangladesh. Brief Evaluation Report. Swiss Dev. Coop., Dhaka.

[8] Bangladesh Bureau of Statistics (2001, 2008-2012) Ministry of Planning, Dhaka.

[9] http://ricepedia.org/bangladesh

[10] http://brri.portal.gov.bd/sites/default/files/files/brri.portal.gov.bd/page/19314eee_5fb5_48c3_801e_cc2f40c0d579/Abo ut BRRI.pdf

[11] Giri, C. and Shrestha, S. (1996) Land Cover Mapping and Monitoring from NOAA AVHRR Data in Bangladesh. International Journal of Remote Sensing, 17, 2749-2759. http://dx.doi.org/10.1080/01431169608949105

[12] Ali, A., Quadir, D.A. and Huh, O.K. (1987) Technical Note. Agricultural, Hydrologic and Oceanographic Studies inBangladesh with NOAA AVHRR Data. International Journal of Remote Sensing, 8, 917-925. http://dx.doi.org/10.1080/01431168708948698

[13] Emch, M. and Peterson, M. (2006) Mangrove Forest Cover Change in the Bangladesh Sundarbans from 1989-2000: A Remote Sensing Approach. Geocarto International, 21, 5-12. http://dx.doi.org/10.1080/10106040608542368

[14] Ahmed, B. and Ahmed, R. (2012) Modeling Urban Land Cover Growth Dynamics Using Multi-Temporal Satellite Images: A Case Study of Dhaka, Bangladesh. International Journal of Geo-Information, 1, 3-31. http://dx.doi.org/10.3390/ijgi1010003

[15] Food and Agriculture Organization of the United Nations (2007) Rome.

[16] Food and Agriculture Organization of the United Nations (1988) AEZ-9 and 28 Categories.

[17] Liu, W. and Yamazaki, F. (2011) Urban Change Monitoring from Multi-Temporal Terra SAR-X Images. Proceedings of the Joint Urban Remote Sensing Event, Munich, 11-13 April 2011, 277-280.

[18] Haque, M.A. (1994) Village and Farm Forestry in Bangladesh. Bangladesh Agricultural University, Mymensingh, and Swiss Agency for Development and Cooperation, Dhaka.

[19] Center for Environment and Geographical Information Services (2006) Study on Livelihood Systems Assessment, Vulnerable Groups' Profiling and Livelihood Adaptation to Climate Hazard and Long Term Climate Change in Drought Prone Areas of NW Bangladesh. Comprehensive Disaster Management Programme, Dhaka.

[20] http://www.dhakamirror.com/headlines/hundreds-of-acres-of-forest-crop-land-water-bodies-destroyed

[21] Azim, M.A., Rashid, M.M., Rahman, M.M., Alam, M.M. and Begum, J. (2007) A Study on Nutritional and Socio -Economic Level of the Rural Household in Gazipur. Pakistan Journal of Nutrition, 6, 138-142. http://dx.doi.org/10.3923/pjn.2007.138.142

[22] Rahman, M.M., Furukawa, Y. and Kawata, I. (2005) Homestead Forest Resources and Their Role in Household Economy: A Case Study in the Villages of Gazipur Sadar Upazila of Central Bangladesh, Small-Scale Forest Economics, Management and Policy, 4, 359-376. 